\title{
PERBANDINGAN KINERJA METODE DETEKSI TEPI PADA PENGENALAN OBJEK MENGGUNAKAN OpenCV
}

\author{
Derisma
}

\author{
Sistem Komputer, Fakultas Teknologi Informasi, Universitas Andalas \\ Kampus Limau Manis, Padang, 2516 \\ E-Mail : : derisma@fti.unand.ac.id
}

\begin{abstract}
ABSTRAK
Deteksi tepi secara luas digunakan dalam pengolahan citra untuk menemukan batas-batas obyek dalam gambar. Dalam makalah ini akan dipelajari teknik deteksi tepi yang paling umum digunakan yaitu metode Sobel, Canny, Laplace dibawah kondisi yang berbeda dengan menggunakan perangkat lunak Visual Studio dan Library OpenCV dan Fltk. Dari percobaan dan pengujian yang dilakukan, maka dapatlah disimpulkan bahwa kecepatan konversi suatu objek dipengaruhi oleh variasi gambar, resolusi gambar, format gambar, spesifikasi kamera, dan spesifikasi laptop yang digunakan. Secara keseluruhan untuk pendektesian tepi lebih efektif menggunakan metode Canny karena output lebih detail dan jelas serta waktu eksekusi paling cepat.
\end{abstract}

Kata Kunci : Deteksi Tepi, Eigenface, OpenCv

\section{PENDAHULUAN}

Deteksi tepi adalah salah satu operasi yang paling mendasar dalam pengolahan gambar dan komputer. Deteksi tepi adalah langkah yang sangat penting menuju pemahaman fitur gambar, banyak digunakan dalam berbagai aplikasi seperti object recognition, analisis gerak, pengenalan pola, pengolahan citra medis, dan lain-lain.

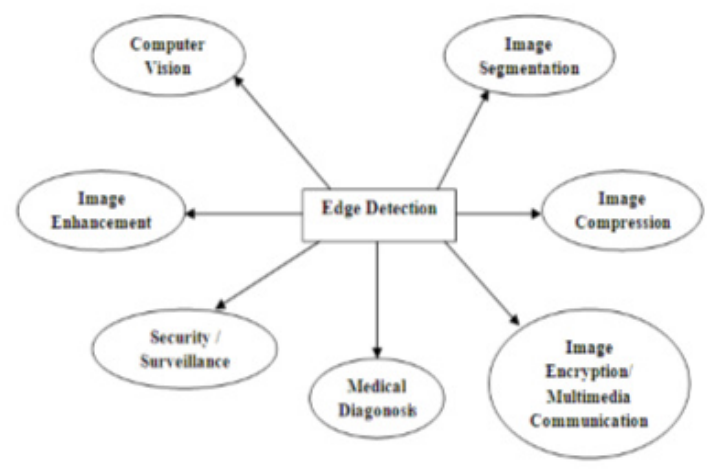

Gambar 1. Penerapan Deteksi Tepi [3]

Pada dasarnya tepi adalah batas antara dua wilayah homogen. Detektor tepi secara luas digunakan dalam visi komputer untuk menemukan perubahan intensitas tajam dan untuk menemukan batas-batas obyek dalam gambar. Deteksi tepi secara signifikan mengurangi jumlah data dan menyaring informasi yang tidak berguna, sementara mempertahankan sifat struktural penting dalam sebuah gambar. Dalam gambar bebas noise, deteksi tepi sangat membantu. Deteksi tepi adalah penelitian yang menantang dalam gambar yang banyak noise dan untuk meningkatkan kinerja gambar kabur. Ada banyak detektor tepi tersedia untuk pre-processing dalam visi komputer. Dalam makalah ini akan dipelajari teknik deteksi tepi yang paling umum digunakan dibawah kondisi yang berbeda dengan menggunakan perangkat lunak Visual Studio dan Library OpenCV dan Fltk. Dengan demikian, akan didapatkan kesimpulan metode deteksi tepi apa yang paling cepat dibawah kondisi yang berbeda-beda tersebut.

\section{TINJAUAN PUSTAKA}

\section{a. Deteksi Tepi}

Deteksi tepi berfungsi untuk memperoleh tepi objek. Deteksi tepi memanfaatkan perubahan nilai intensitas yang drastis pada batas dua area. Definisi tepi di sini adalah "himpunan piksel yang terhubung yang terletak pada batas dua area" [6]. Deteksi tepi dapat dibagi menjadi dua golongan. Golongan pertama disebut deteksi tepi orde pertama, yang bekerja dengan menggunakan turunan atau diferensial orde pertama. Termasuk kelompok ini adalahoperator Roberts, Prewitt, dan Sobel. Golongan kedua dinamakan deteksi tepi orde kedua, yang menggunakan turunan orde kedua. Contoh yang termasuk kelompok ini adalah Laplacian of Gaussian (LoG). Berbagai teknik deteksi tepi bekerja dengan cara yang berbeda. Masing-masing memiliki kekuatan [2]. Itulah sebabnya, eksperimen pada suatu aplikasi dengan menggunakan berbagai teknik deteksi tepi perlu dilakukan untuk mendapatkan hasil yang terbaik.

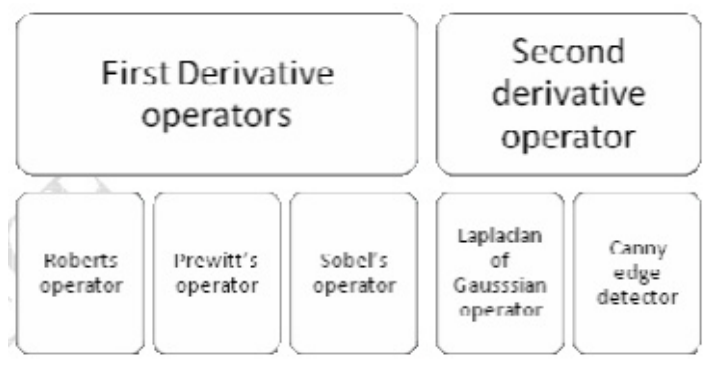

Gambar 2. Gaussian Derivative Kernel [6] 


\section{b. Operator Sobel}

Sobel merupakan metode edge detection yang termasuk dalam gradient edge detector. Piksel dari sebuah gambar yang akan dilakukan pendeteksian batas (edge) akan menjadi sebuah edge jika piksel tersebut melewati batas (threshold) tertentu. Sehingga apabila threshold telah ditetapkan maka nilai dari setiap piksel dapat kita tentukan apakah piksel tersebut merupakan batas atau bukan. Operator Sobel melakukan deteksi tepi dengan memperhatikan tepi vertical dan horizontal. [3] [4][9][12][13][14]

Gradient Magnitude dari operator Sobel adalah sebagai berikut :

$$
\begin{gathered}
G[f(x, y)]=\sqrt{G_{x}^{2}+G_{y}^{2}} \\
|\mathrm{G}|=\left|\mathrm{G}_{\mathrm{x}}\right|+\left|\mathrm{G}_{\mathrm{y}}\right|
\end{gathered}
$$

\begin{tabular}{|l|l|l|}
\hline-1 & 0 & +1 \\
\hline-2 & 0 & +2 \\
\hline-1 & 0 & +1 \\
\hline
\end{tabular}

Gx

\begin{tabular}{|c|c|c|}
\hline+1 & +2 & +1 \\
\hline 0 & 0 & 0 \\
\hline-1 & -2 & -1 \\
\hline
\end{tabular}

Gy
Gambar 3. Operator Sobel

Pendeteksian batas dari sebuah gambar dilakukan dengan melakukan operasi martiks sobel terhadap gambar yang akan dilakukan pendeteksian gambar. Matriks sobel merupakan matriks yang berukuran 3 x 3 dengan koefisien yang telah ditentukan.

\section{c. Operator Canny}

Canny detektor dikembangkan oleh John F. Canny pada tahun 1986. Juga dikenal sebagai detektor optimal, algoritma Canny bertujuan untuk memenuhi tiga kriteria utama:

1. Tingkat kesalahan rendah

2. Lokalisasi yang bagus: jarak antara tepi piksel terdeteksi dan tepi nyata piksel dapat diminimalkan.

3. Tanggapan minimal: hanya satu respon detektor per tepi.

Pendekatan algoritma canny dilakukan dengan konvolusi fungsi gambar dengan operator gaussian dan turunan-turunannya. Turunan pertama dari fungsi citra yang dikonvolusikan dengan fungsi gaussian,

$$
g(x, y)=D[\operatorname{gauss}(x, y) * f(x, y)]
$$

Ekivalen dengan fungsi citra yang dikonvolusikan dengan turunan pertama dari fungsi gaussian,

$$
g(x, y)=D[\operatorname{gauss}(x, y)] * f(x, y)
$$

\section{d. Operator Laplace}

Disebut juga dengan Metode Laplacian of Gaussian (log). Deteksi tepi orde kedua yang makin kurang sensitif terhadap derau adalahLaplacian of Gaussian (LoG). Hal ini disebabkan penggunaan fungsi Gaussian yang memuluskan citra dan berdampak pada pengurangan derau pada citra. Akibatnya, operator mereduksi jumlah tepi yang salah terdeteksi [2]. Menurut Fisher, dkk. [5], operator LoG diperoleh melalui konvolusi dengan

$$
\operatorname{LoG}(y, x)=-\frac{1}{\pi \sigma^{4}}\left[1-\frac{x^{2}+y^{2}}{2 \sigma^{2}}\right] e^{\frac{-\left(x^{2}+y^{2}\right)}{2 \sigma^{2}}}
$$

Fungsi di atas disebut sebagai filter topi Meksiko (the Mexican hat filter) karena bentuknya seperti topi yang biasa dikenakan orang Meksiko. Dalam hal ini, semakin besar nilai, semakin besar pula cadar yang diperlukan.Contoh cadar berukuran 5 x 5 yang mewakili operator LoG ditunjukkan pada Gambar 4 [6].

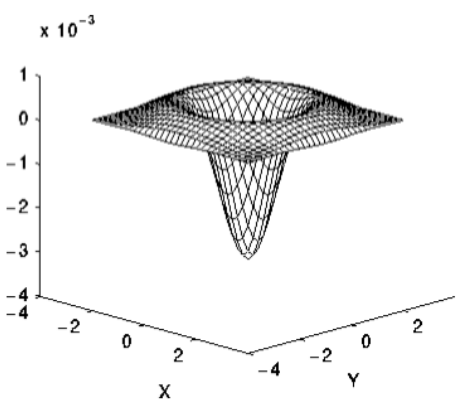

Gambar 4. Fungsi LoG(y, x) [6]

\section{e. OpenCV}

Open CV adalah singkatan dari Open Computer Vision yaitu library library open source yang dikhususkan untuk melakukan image prosesing. OpenCV memiliki keuntungan menjadi kerangka multi-platform; mendukung Windows dan Linux, dan baru-baru, Mac OS X. Ada banyak fungsi deteksi tepi yang tersedia pada OpenCV diantaranya cvCanny, cvLaplace, cvSobel, dll [10][15]

\section{HASIL DAN PEMBAHASAN}

Pendeteksian tepi diawali dengan mengambil variasi gambar wajah, tanda tangan, sidik jari dan plat mobil sebagai input gambar. Selanjutnya dengan menggunakan library Open $\mathrm{Cv}$ gambar tersebut di konversi ke grayscale krmudian dilakukan operasi deteksi tepi, setelah itu akan ditanpilkan hasil deteksi tepi dengan lamanya waktu pemrosesan. 


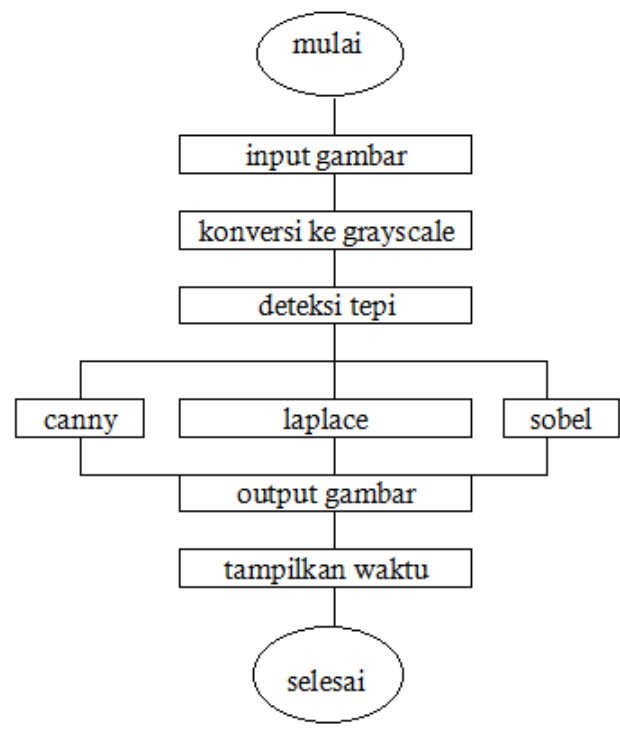

Gambar 5. Flowchart Program

Pada program ini digunakan banyak function, dimana setiap button action mengarah kepada satu function, jadi ketika salah satu button action di klik, maka program akan menjalankan sub programnya, pada program ini digunakan 2 library, yaitu dari opencv dan fltk, untuk membuat interface pada program ini digunakan library fltk dan untuk mengolah gambarnya digunakan library dari opencv.

Program ini terdiri dari empat function dan satu program utama, program utama inilah yang akan mengarah ke sub sub program lainnya, lalu terdapat 4 function program, yaitu untuk mengakses gambar, mengolah gambar dengan metoda canny, mengolah gambar dengan metoda sobel, dan metoda laplace.

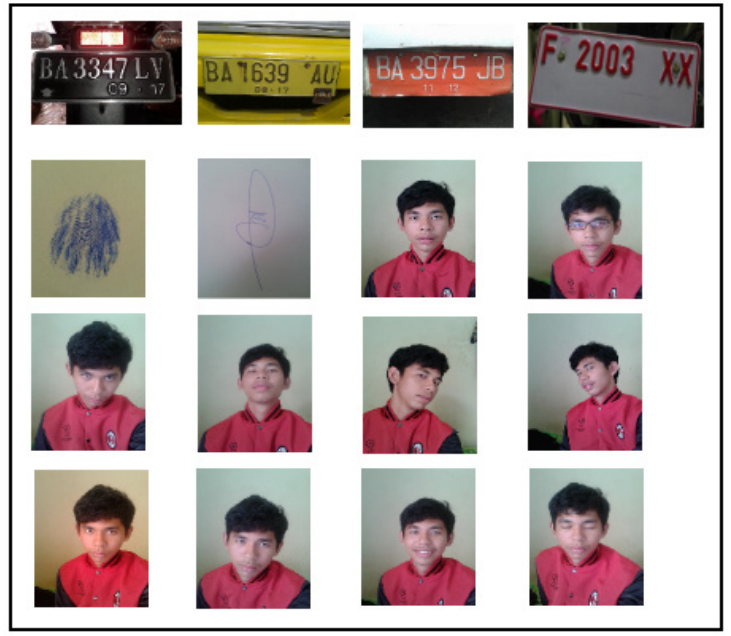

Gambar 6. Input Gambar

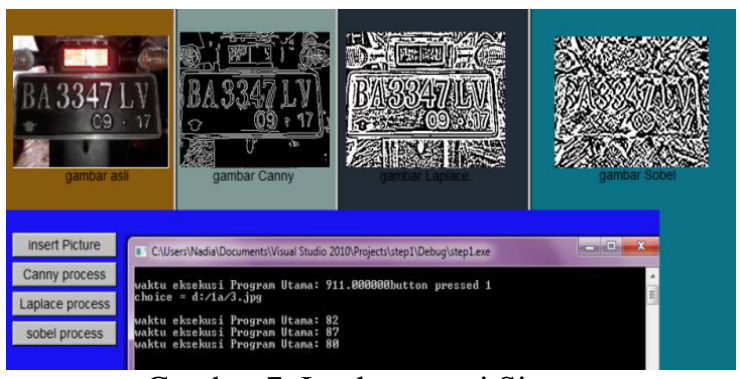

Gambar 7. Implementasi Sistem

Terdapat varian ukuran gambar ukuran 200x267 px, dan 300x400 px, kamera dengan resolusi $5 \mathrm{mp}, 12.5 \mathrm{mp}, 20 \mathrm{mp}$, varian merk laptop yaitu Toshiba L40 Processor intel core I5, Asus A43SD Processor intel core I5, Dell inspiron Processor intel core I3, Toshiba L50010 Processor intel dual core.

Dari Tabel 1 untuk gambar dengan ukuran 200x267 px, resolusi $5 \mathrm{mp}$, Toshiba L40 Processor intel core I5 (dalam satuan ms) didapatkan hasil deteksi tepi dengan metode laplace membutuhkan waktu paling besar untuk tige gambar dengan format tiff, sedangkan metode canny membutuhkan waktu paling sedikit dengan format bmp. Untuk variasi gambar dengan ukuran yang sama, didapatkan deteksi tepi untuk plat mobil yang berwarna putih membutuhkan waktu paling lama mengkonversi objek dengan lebih detail. sedangkan deteksi tepi dengan gambar wajah tampak depan membutuhkan waktu paling sedikit.

Tabel 1. Edge Detection untuk gambar dengan ukuran 200x267 px, resolusi $5 \mathrm{mp}$, Toshiba L40 Processor intel core I5 (dalam satuan ms)

\begin{tabular}{|c|c|c|c|c|c|c|c|c|c|c|c|c|c|}
\hline \multirow{2}{*}{\multicolumn{2}{|c|}{ Variasi Gambar }} & \multicolumn{4}{|c|}{ canny } & \multicolumn{4}{|c|}{ laplace } & \multicolumn{4}{|c|}{ sobel } \\
\hline & & jpg & bmp & png & tiff & $\mathrm{jpg}$ & bmp & png & tiff & $\mathrm{jpg}$ & bmp & png & tiff \\
\hline \multicolumn{14}{|c|}{ WAJAH } \\
\hline & wajah tampak depan & 29.9 & 15 & 41.9 & 59.9 & 49.9 & 33.9 & 52.9 & 72.9 & 39.9 & 30.9 & 50.9 & 74.9 \\
\hline & wajah serong kiri $\left(20^{\circ}\right)$ & 28.9 & 19 & 37.9 & 62.9 & 42.9 & 33.9 & 54.9 & 81 & 41.9 & 36.9 & 49.9 & 62.9 \\
\hline & $=$ wajah serong kanan $\left(20^{\circ}\right)$ & 27.9 & 19 & 29.9 & 50.9 & 39.9 & 34.9 & 52.9 & 73.9 & 40.9 & 34.9 & 49.9 & 63.9 \\
\hline d & wajah tengadah $\left(10^{\circ}\right)$ & 26.9 & 20.9 & 36.9 & 58.9 & 42.9 & 33.9 & 53.9 & 73.9 & 40.9 & 30.9 & 50.9 & 63.9 \\
\hline e & wajah menunduk $\left(10^{\circ}\right)$ & 30.9 & 19 & 41.9 & 56.9 & 43.9 & 33.9 & 53.9 & 69.9 & 40.9 & 30.9 & \begin{tabular}{|l|l|}
49.9 \\
\end{tabular} & 62.9 \\
\hline$f$ & wajah tersenyum & 22.9 & 19 & 37.9 & 58.9 & 42.9 & 34.9 & 61.9 & 72.9 & 40.9 & 31.9 & 40.9 & 71.9 \\
\hline & wajan ketawa & 29.9 & 19 & 37.9 & 60.9 & 43.9 & 74.9 & 53.9 & 73.9 & 40.9 & 27.9 & 49.9 & 84 \\
\hline h & wajah sedih & 21.9 & 19 & 33.9 & 59.9 & 43.9 & 33.9 & 44.9 & 58.9 & 40.9 & 31.9 & 38.9 & 57.9 \\
\hline & wajah marah & 28.9 & 16 & 39.9 & 61.9 & 43.9 & 35.9 & 52.9 & 74.9 & 42.9 & 24.9 & 53.9 & 71.9 \\
\hline & wajah dgn mata tertutup & 29.9 & 19.9 & 39.9 & 62.9 & 45.9 & 33.9 & 52.9 & 74.9 & 45.9 & 31.9 & 49.9 & 62.9 \\
\hline k & wajah pakai kaca mata & 28.9 & 20.9 & 40.9 & 59.9 & 44.9 & 33.9 & 45.9 & 74.9 & 40.9 & 31.9 & 50.9 & 72.9 \\
\hline \multicolumn{2}{|c|}{2 tandatangan } & 24.9 & 16 & 32.9 & 55.9 & 42.9 & 34.9 & 41.9 & 74.9 & 39.9 & 31.9 & 49.9 & 68.9 \\
\hline \multicolumn{2}{|c|}{3 sidikjari } & 28.9 & 16 & 25.9 & 52.9 & 43.9 & 33.9 & 53.9 & 76 & 41.9 & 30.9 & 50.9 & 71.9 \\
\hline \multicolumn{14}{|c|}{4 plat mobil } \\
\hline & hitam & 35.9 & 19.9 & 89 & 97 & 44.9 & 33.9 & 52.9 & 76 & 48.9 & 30.9 & 50.9 & 74.9 \\
\hline b & o merah & 27.9 & 19 & 36.9 & 58.9 & 42.9 & 33.9 & 41.9 & 73.9 & 40.9 & 31.9 & \begin{tabular}{|l|l}
49.9 \\
\end{tabular} & 93 \\
\hline & kuning & 31.9 & 21.9 & 40.9 & 63.9 & 43.9 & 32.9 & 50.9 & 76 & 43.9 & 30.9 & 68.9 & 72.9 \\
\hline & puth & 46.9 & 32.9 & 59.9 & 86 & 71.9 & 53.9 & 84 & 120 & 64.9 & 50.9 & 81 & 118 \\
\hline & rata-rata & 29.61 & 19.6 & 41.4 & 62.9 & 45.6 & 37.7 & 53.3 & 76.4 & 43.4 & 32.5 & 52.2 & 73.5 \\
\hline
\end{tabular}


Tabel 2. Edge Detection Comparison untuk gambar dengan ukuran 300x400 px, resolusi 5 $\mathrm{mp}$, Dell inspiron Processor intel core I3 (dalam satuan ms)

\begin{tabular}{|c|c|c|c|c|c|c|c|c|c|c|c|c|c|}
\hline \multirow{2}{*}{\multicolumn{2}{|c|}{ Variasi Gambar }} & \multicolumn{4}{|c|}{ canny } & \multicolumn{4}{|c|}{ Iaplace } & \multicolumn{4}{|c|}{ sobel } \\
\hline & & jpg & $\mathrm{bmp}$ & png & tiff & jpg & bmp & png & tiff & jpg & $\mathrm{bmp}$ & png & tiff \\
\hline \multicolumn{14}{|c|}{ WAJAH } \\
\hline a & wajah tampak depan & 54.9 & 44.9 & 81 & 132 & 94 & 70.9 & 111 & 163 & 88 & 66.9 & 84 & 162 \\
\hline b & wajah serong kiri $\left(20^{\circ}\right)$ & 47.9 & 39.9 & 70.9 & 123 & 92 & 70.9 & 110 & 169 & 89.9 & 65 & 111 & 161 \\
\hline & wajah serong kanan $\left(20^{\circ}\right)$ & 64.9 & 34 & 122 & 167 & 93 & 68.9 & 120 & 157 & 89 & 63.9 & 109 & 160 \\
\hline d & wajah tengadah $\left(10^{\circ}\right)$ & 49.9 & 32 & 89.9 & 136 & 93 & 73.9 & 115 & 157 & 93 & 65 & 108 & 178 \\
\hline e & wajah menunduk $\left(10^{\circ}\right)$ & 55.9 & 62.9 & 77 & 127 & 90 & 73.9 & 116 & 161 & 94 & 66.9 & 107 & 156 \\
\hline$f$ & wajah tersenyum & 54.9 & 33.9 & 90 & 147 & 91 & 70.9 & 114 & 161 & 94 & 64.9 & 108 & 167 \\
\hline & wajah ketawa & 55 & 39.9 & 90 & 132 & 94 & 68.9 & 110 & 160 & 95 & 64.9 & 109 & 154 \\
\hline & wajah sedih & 53.9 & 32.9 & 78 & 127 & 105 & 71.9 & 112 & 163 & 97 & 67.9 & 109 & 153 \\
\hline & wajah marah & 58.9 & 74 & 85 & 159 & 93 & 64.9 & 110 & 161 & 85 & 64.9 & 110 & 179 \\
\hline & wajah dgn mata tertutup & 53.9 & 63.9 & 90 & 130 & 94 & 68.9 & 110 & 157 & 85 & 65.9 & 109 & 167 \\
\hline k & wajah pakai kaca mata & 56.9 & 39.9 & 98 & 147 & 91 & 70.9 & 114 & 161 & 95 & 71.9 & 107 & 156 \\
\hline & & & & & & & & & & & & & \\
\hline \multicolumn{2}{|c|}{ tandatangan } & 47.9 & 32.9 & 68.9 & 136 & 90 & 76 & 115 & 160 & 84 & 65.9 & \begin{tabular}{|l|l|}
84 & \\
\end{tabular} & 159 \\
\hline \multicolumn{2}{|c|}{3 sidikjari } & 67.9 & 39.9 & 90 & 130 & 68.9 & 68.9 & 79.9 & 157 & 68.9 & 68.9 & 79.9 & 148 \\
\hline \multicolumn{14}{|c|}{4 plat mobil } \\
\hline & hitam & 66.9 & 44.9 & 130 & 167 & 94 & 69.9 & 113 & 163 & 86 & 66.9 & 84 & 167 \\
\hline & merah & 53.9 & 62.9 & 70.9 & 123 & 92 & 68.9 & 111 & 157 & 87 & 65.9 & 105 & 156 \\
\hline & kuning & 64.9 & 63.9 & 81 & 132 & 91 & 70.9 & 109 & 157 & 91 & 65.9 & 110 & 160 \\
\hline & putih & 87 & 61.9 & 122 & 204 & 147 & 112 & 141 & 263 & 138 & 107 & 170 & 233 \\
\hline & rata-rata & 58.56 & 47.3 & 90.3 & 142 & 94.9 & 73 & 112 & \begin{tabular}{|l|}
166 \\
\end{tabular} & 91.8 & 68.7 & 106 & 166 \\
\hline
\end{tabular}

Dari Tabel 2 untuk gambar dengan ukuran 300x400 px, resolusi $5 \mathrm{mp}$, Dell inspiron Processor intel core I3 (dalam satuan ms) didapatkan hasil deteksi tepi dengan metode laplace dan sobel membutuhkan waktu paling besar untuk tige gambar dengan format tiff, sedangkan metode canny membutuhkan waktu paling sedikit dengan format bmp. Untuk variasi gambar dengan ukuran yang sama, didapatkan deteksi tepi untuk plat mobil yang berwarna putih membutuhkan waktu paling lama mengkonversi objek dengan lebih detail, Laplace menghasilkan tepi yang lebih tebal. Sedangkan sobel kehilangan banyak tepi sehingga menjadi tidak jelas.

Jika hasil pengujian dari Tabel 1 dengan Tabel 2 dibandingkan, didapatkan di atas dihasilkan waktu eksekusi yang bervariasi. Kecepatan mengkonversi gambar di pengaruhi oleh spesifikasi laptop terutama prosesor dan memori karena mengkonversi gambar dapat memakan banyak memori. Selain itu menjalankan aplikasi pendeteksi tepi ini menggunakan beberapa gambar dengan ukuran yang berbeda akan menghasilkan lama waktu eksekusi program yang berbeda pula. Ukuran gambar yang lebih besar membutuhkan waktu eksekusi yang lebih lama. Penggunaan kamera/web kamera yang berbeda,tentunya juga mempengaruhi waktu dekteksi yang dihasilkan. Kamera dengan spesifikasi yang lebih tinggi memiliki kualitas gambar dan komposisi gambar yang lebih baik. Semakin baik gambar yang dihasilkan, ukurannya juga akan semakin besar, maka waktu pendeteksian juga semakin lama. Dari Gambar 8 didapat kesimpulan waktu eksekusi paling rendah untuk semua keadaan adalah metode canny dan waktu eksekusi paling lama adalah metode laplace.

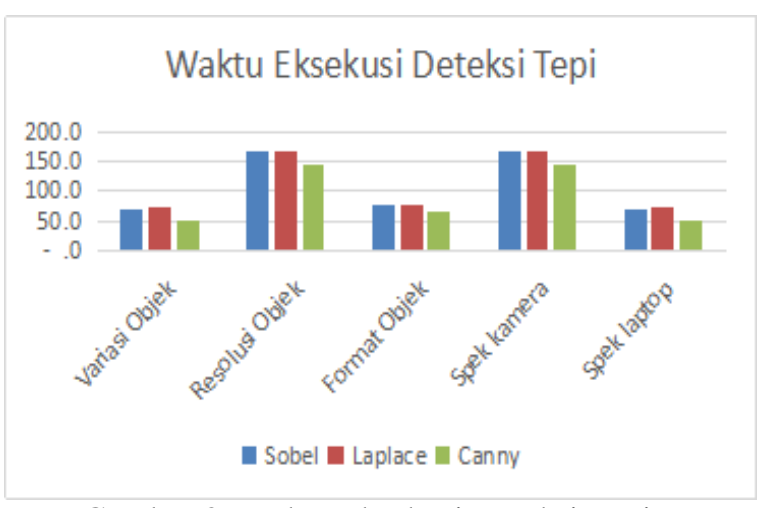

Gambar 8. Waktu Eksekusi Deteksi Tepi

\section{KESIMPULAN}

Dari percobaan dan pengujian yang dilakukan, maka dapatlah disimpulkan bahwa kecepatan konversi suatu objek sangat dipengaruhi oleh variasi gambar, resolusi gambar, format gambar, spesifikasi kamera, spesifikasi laptop yang digunakan. Kecepatan mengkonversi gambar di pengaruhi oleh spesifikasi laptop terutama prosesor dan memori karena mengkonversi gambar dapat memakan banyak memori. Secara keseluruhan untuk pendektesian tepi lebih efektif menggunakan metode Canny karena waktu eksekusi paling cepat dibandingkan yang lain.

\section{DAFTAR PUSTAKA}

[1]. A Kadir, A.Susanto, 2013, Teori dan Aplikasi Pengolahan Citra, penerbit Andi. Yogyakarta.

[2]. Crane, R.1997. A Simplified Approach to Image Processing Classical and Modern Techniques in C. Upper Saddle River: Prentice Hall PTR.

[3]. Dr.S.Vijayarani1, Mrs.M.Vinupriya, 2013, Performance Analysis of Canny and Sobel Edge Detection Algorithms in Image Mining, International Journal of Innovative Research in Computer and Communication Engineering, Vol. 1, Issue 8

[4]. Er. Komal Sharma, Er. Navneet Kaur, 2013, Comparative Analysis of Various Edge Detection Techniques, Volume 3, Issue 12, December.

[5]. Fisher, R.; Perkins, S.; Walker, A.; Wolfart, F. 2003. Roberts Cross Edge detector. [Online]. homepages.inf.edu.ac.uk.rbf/HOPR2/Roberts.ht m.

[6]. G. Kamdar, C. H. Vithalani, 2012, Wavelet Based Edge Detection Technique, Journal of Information Knowledge and Research In Electronics and communication Engineering, Vol 02, Issue 01

[7]. Gonzalez, R.C.; Woods, R.E. 2002.Digital Image Processing. Prentice Hall.

[8]. P Tiwari Edge, 2015, Detection Algorithms- A Review, International Journal of Computer Science and Information Technology Researc, Vol. 3, Issue 4, pp: (9 12), 
[9]. Ireyuwa. E. Igbinosa, 2013, Comparison of Edge Detection Technique in Image Processing Techniques, International Journal of Information Technology and Electrical Engineering, Volume 2, Issue 1

[10]. Intel. 1999-2001. Open Source Computer Vision Library, Reference Manual. Intel Corporation.

[11]. Li Bin, Mehdi Samiei yeganeh, 2012. Comparison for Image Edge Detection Algorithms, IOSR Journal of Computer

Engineering (IOSRJCE), Volume 2, Issue 6 , PP 01-04

[12]. Pooja Sharma1,Gurpreet Singh2, Amandeep Kaur3, 2013, Different Techniques Of Edge Detection In Digital Image Processing, International Journal of Engineering Research and Applications (IJERA), Vol. 3, Issue 3, Jun, pp.458-461
[13]. U.I. Bature, Murtala A. B., A. Y. Nasir.2015, Evaluation Of Image Detection Techniques. Journal of Multidisciplinary Engineering Science and Technology (JMEST). Vol. 2 Issue 12,

[14]. Y.Ramadevi, T.Sridevi, B.Poornima, B.Kalyani , 2010, Segmentation and Object Recognition Using Edge Detection Techniques, International Journal of Computer Science \& Information Technology (IJCSIT), Vol 2, No 6, December [15]. http://docs.opencv.org 